\title{
Morphological, molecular, and chromosomal identification of dwarf haploid parthenosporophytes of Tauya basicrassa (Phaeophyceae, Laminariales) from the Sea of Okhotsk
}

\author{
Tatyana A. Klochkova ${ }^{1,2}$, Nina G. Klochkova ${ }^{2}$, Norishige Yotsukura ${ }^{3}$ and Gwang Hoon Kim ${ }^{1, *}$ \\ ${ }^{1}$ Department of Biology, Kongju National University, Kongju 32588, Korea \\ ${ }^{2}$ Kamchatka State Technical University, Petropavlovsk-Kamchatsky 683003, Russia \\ ${ }^{3}$ Field Science Center for Northern Biosphere, Hokkaido University, Sapporo 060-0809, Japan
}

Morphological, molecular and chromosomal studies were carried out on Tauya basicrassa, an endemic kelp species distributed on the northern continental coast of the Sea of Okhotsk in Russia. The sporophytes of T. basicrassa grow up to 3-6 $\mathrm{m}$ long, 1.8-2.2 $\mathrm{m}$ wide, and 6.5-7 $\mathrm{kg}$ wet weight. The thallus has a blade with very thick narrow basal portion and thinner and much broader upper portion, which usually splits into 3 bullated lobes. A dwarf laminariacean alga, which did not show any morphological similarity to the other species of the order Laminariales, was found from the same locality. The blade of this alga is thin and soft, reached $26-34 \mathrm{~cm}$ long and 6-6.5 $\mathrm{cm}$ wide and had 4 longitudinal rows of bullations that covered the entire blade. Molecular analysis showed that the dwarf alga has $100 \%$ sequence identity in plastid-encoded RuBisCo spacer, mitochondrial cytochrome $\mathrm{c}$ oxidase subunit 1 and nuclear-encoded rDNA genes with normal sporophytes of T. basicrassa, indicating that they are different life forms of the same species. Fluorescent DAPI staining showed that the nucleus in the normal sporophyte was 50-65\% larger than those of the dwarf ones. Chromosome count using acetocarmine staining showed $\mathrm{n}=\mathrm{ca} .20$ for the normal sporophytes of $T$. basicrass $a$ and $\mathrm{n}=\mathrm{ca}$. 10 for the dwarf one. These results suggest that the dwarf thallus is a haploid parthenosporophyte of T. basicrassa, which developed in nature. This is the first evidence of parthenosporophytes of the laminariacean algae occurring naturally in the field.

Key Words: chromosome; endemic kelp; Laminariales; molecular phylogeny; morphology; parthenosporophyte; Sea of Okhotsk; Tauya basicrassa

\section{INTRODUCTION}

The brown algae belonging to kelp species are one of the most intensively studied seaweeds due to their wide commercial application and consumption as food and medicine. It was believed that the generic composition of kelp in the world ocean was established by the end of last century (Wynne 1982), therefore new discovery of the endemic genus, Tauya Kloczcova et Krupnova from
Russia containing a single species, T. basicrassa, was unexpected and exciting (Klochkova and Krupnova 2004). The genus Tauya was described from Taui Bay (Russian: Tauyskaya Guba) located on the northern continental coast of the Sea of Okhotsk. This remote and sparsely populated northern area has harsh, almost Arctic climate (Klochkova et al. 2010, 2012, 2013), but at the same time
(9) $\$$ This is an Open Access article distributed under the terms of the Creative Commons Attribution Non-Commercial License (http://creativecommons.org/licenses/by-nc/3.0/) which permits unrestricted non-commercial use, distribution, and reproduction in any medium, provided the original work is properly cited.
Received October 20, 2016, Accepted January 31, 2017

* Corresponding Author

E-mail: ghkim@kongju.ac.kr

Tel: +82-41-850-8504, Fax: +82-41-850-8479 

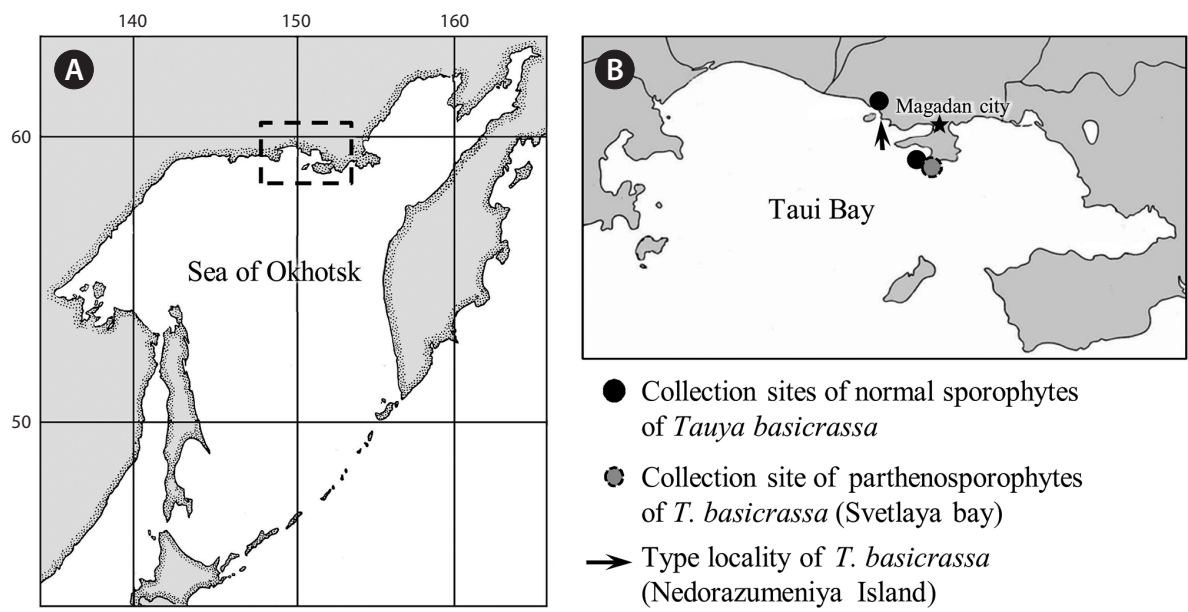

Fig. 1. Collection sites of samples from the Sea of Okhotsk used in this study. Surveyed coastal area is marked with dashed frame (A) and shown as separate enlarged image (B).

it is the most phycologically well-studied area in the Sea of Okhotsk. It was therefore surprising that the giant kelp species such as Tauya was overlooked until 2004 (Klochkova and Belij 2006).

Nowadays, the systematics of kelp genera and species is based on the DNA analysis, rather than on morphology and anatomy (Cho et al. 2006, Lane et al. 2006, Boo et al. 2011). The morphological characteristics of genera often contradicted to the results of genetic analysis, and traditionally used taxonomic key characters became somewhat obsolete in case of kelp. As the description of $T$. basicrassa was based on morphology and anatomy without any molecular-phylogenetic analysis, it has been regarded as Laminariales familia incertae sedis (uncertain family) (Guiry and Guiry 2016).

During hydrobiological expedition held in July 2008 we found an unusual small kelp species at the depth of $7 \mathrm{~m}$ in Svetlaya bay, which is located inside Taui Bay. It had several morphological characters clearly distinguishable from other described kelp species from the Sea of Okhotsk and any kelp genus known to date. While analyzing our underwater videos of seaweed beds, it became apparent that such unusual plants were very rarely distributed in other areas of Taui Bay. First information about this species was published in Klochkova and Belij (2010) and later in the book on seaweed flora of the northern coast of the Sea of Okhotsk (Klochkova et al. 2013). We preliminarily applied the name Laminaria sp. and called it "bullate small kelp" until further genetic information is available (Klochkova et al. 2013).

In this paper, we present first molecular-phylogenetic analysis of T. basicrassa and "bullate small kelp" based on the plastid-encoded RuBisCo spacer, mitochondrial cyto- chrome c oxidase subunit 1 (COI) and nuclear-encoded rDNA sequences. Unexpectedly, they turn out to be genetically identical, indicating that they are different life forms of the same species. Ploidy levels of both morphotypes were analyzed using fluorescent DAPI staining and chromosome counting.

\section{MATERIALS AND METHODS}

\section{Sample collection and specimen observation}

Samples of Tauya basicrassa were collected with SCUBA diving and also cast ashore during hydrobiological expedition held in July 2008 on the northern continental coast of the Sea of Okhotsk (Belij 2013, Klochkova et al. 2013). Collection sites inside Taui Bay included Nedorazumeniya Island (type locality) and Svetlaya bay (Fig. 1). We also re-investigated type specimen (Fig. 2A \& B) currently preserved in Kamchatka State Technical University (type information: Russia, Sea of Okhotsk, Taui Bay, Nedorazumeniya Island, depth $15 \mathrm{~m}$, coll. on Jul 16, 2000 , by T. N. Krupnova). It should be noted that the type specimen is in a fragile condition, because unlike other kelp specimens, large thin blades of $T$. basicrassa are very fragile when dried and they crack and crumble easily. We also studied another specimen of T. basicrassa collected in June 1975 from Taui Bay by L. Prudnikova, provided for our herbarium collection by TINRO-center (Vladivostok, Russia) (Fig. 2C). For the estimation of plant age, we counted the number of annual rings on the cross-section of stipes and analyzed overall plant morphology (Klochkova et al. 2012). For microscopic observations, small 

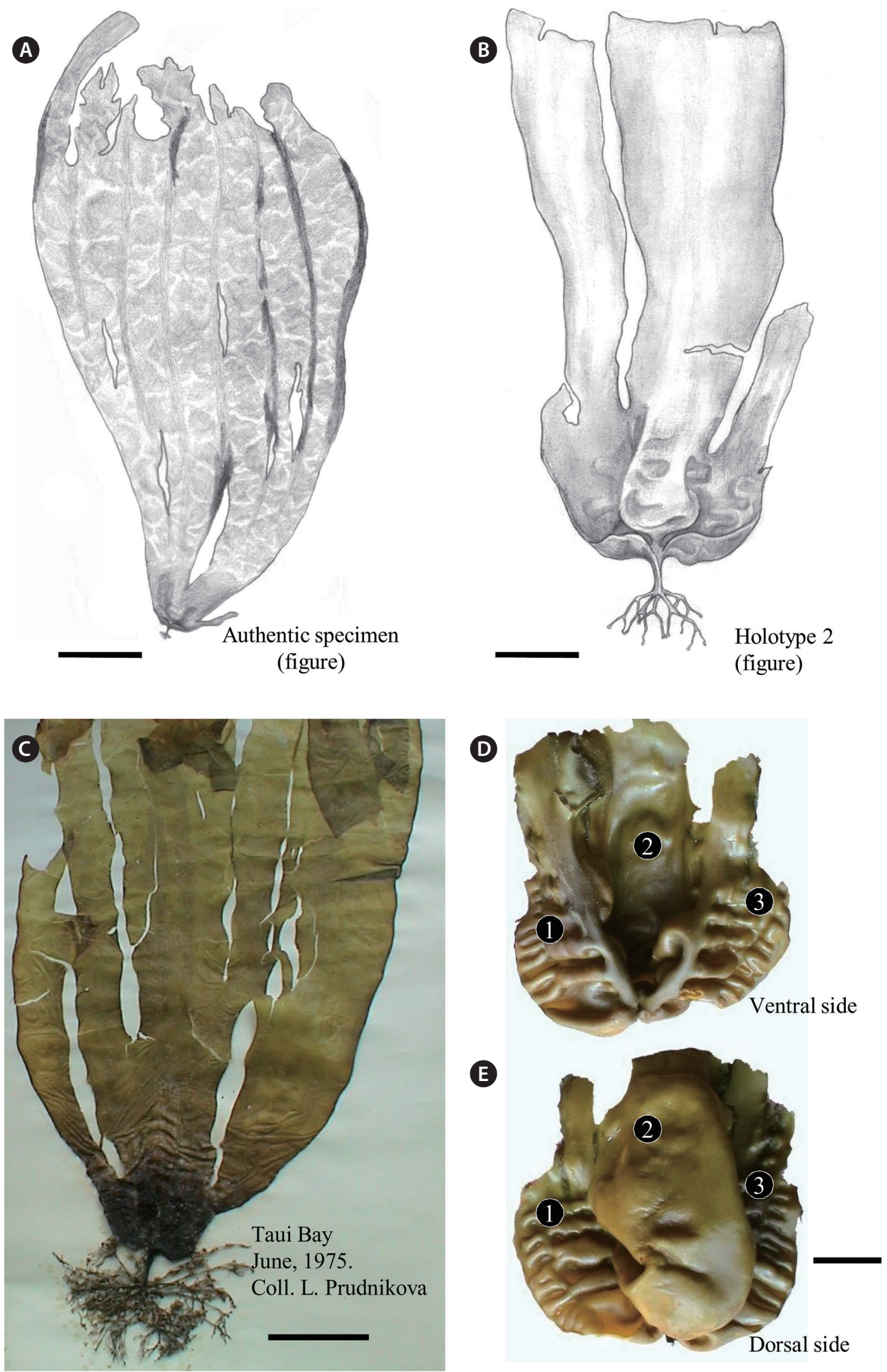

Fig. 2. Sporophytic plants of Tauya basicrassa from the Sea of Okhotsk. (A) Drawing of the authentic specimen showing a deep-water plant with large undissected blade with several longitudinal clefts (Nedorazumeniya Island). (B) Drawing of holotype specimen collected from the upper sub-tidal zone (reproduced with permission from Klochkova and Krupnova 2004). (C) Dry specimen collected by L. Prudnikova on June 1975 from Taui Bay (Sea of Okhotsk). In herbarium specimens, the basal part of blade becomes much darker. (D \& E) Dorsal and ventral sides of the basal part of same blade, showing a concave-convolute hood-like structure with bullations. Three distinct portions are marked with numerals. Scale bars represent: $A, 50 \mathrm{~cm} ; B, 4 \mathrm{~cm} ; C, 7 \mathrm{~cm} ; D$ \& $E, 2 \mathrm{~cm}$. 
pieces of plants were incised from different parts of the blades. They were rehydrated in sterilized seawater, cut with a fine razor blade, and observed under a light microscope. Micrographs were taken with Olympus DP50 digital camera affixed to an Olympus BX50 microscope (Olympus, Tokyo, Japan) using Viewfinder Lite and Studio Lite computer programs (Better Light Inc., Placerville, CA, USA).

\section{Molecular identification and phylogenetic anal- ysis}

For extraction of genomic DNA, pieces of plants incised from different parts of the blades were rehydrated in sterilized seawater and their surface was thoroughly cleaned with a fine brush. They were transferred to 2.0$\mathrm{mL}$ cryotubes and frozen in liquid nitrogen. The best results were obtained when tissue for DNA extraction was obtained from the basal part of blade. The cryotubes containing pieces of plants were shaken at 5,000 rev $\mathrm{min}^{-1}$ for 2 min with a cell homogenization machine. The DNA was then extracted using an Invisorb Spin Plant Mini Kit (Invitek, Berlin-Buch, Germany) with some modifications of the manufacturer's protocol that we applied in case of extracting DNA from the kelp samples. The plastid-encoded RuBisCo spacer was amplified using primer sets RS1-RS2, KR3-KR4, nuclear-encoded rDNA was amplified with the primer sets LB1-BC2 (ITS1 region) and YB1-LB2 (ITS2 region), and mitochondrial COI gene was amplified using the primer set GazF2-GazR2 (Saunders and Druehl 1993, Yoon and Boo 1999, Yoon et al. 2001, Lane et al. 2006, 2007). TaKaRa Ex Taq polymerase (Takara Biomedicals, Otsu, Japan) was used for the PCR amplifications. The following PCR program was used: initial denaturation at $95^{\circ} \mathrm{C}$ for $4 \mathrm{~min}$, followed by 35 cycles of denaturation at $94^{\circ} \mathrm{C}$ for $30 \mathrm{~s}$, annealing at $55^{\circ} \mathrm{C}$ for $30 \mathrm{~s}$, extension at $72^{\circ} \mathrm{C}$ for $1.5 \mathrm{~min}$ and a final extension at $72^{\circ} \mathrm{C}$ for $10 \mathrm{~min}$. PCR products were checked on an agarose gel for length, concentration, and purity. Sequencing was performed commercially (Cosmogenetech Co., Ltd., Seoul, Korea). On the total, we sequenced $981 \mathrm{nt}$ for rDNA regions in both samples (18S rRNA, ITS1, 5.8S rRNA, ITS2, and 26S rRNA). For RuBisCo spacer, $633 \mathrm{nt}$ were sequenced including partial $r b c \mathrm{~L}$ and $r b c \mathrm{~S}$, and for COI gene, $396 \mathrm{nt}$ were sequenced.

Our new sequences and sequences from GenBank (National Center for Biotechnology Information 2016) were aligned using Geneious (ver. 7.1.8; Biomatters, Auckland, New Zealand) and the alignments were refined by eye. For rDNA alignment, our sequences were trimmed up to $619 \mathrm{nt}$ to match the alignment length of other sequences from the NCBI; total alignment was 744 nt-long with 125 indels/gaps. RuBisco alignment was 653 nt-long with 20 indels/gaps. The trees were generated using Bayesian phylogenetic analysis (MrBayes 3.2.2) (Huelsenbeck and Ronquist 2001) using a GTR substitution model, 3,000,000 generations, sub-sampled every 1,000 generations and a burn-in length of 300,000 generations. Maximum likelihood analysis used RAxML 7.2.8 (Stamatakis 2014) using a GTR + gamma model. Bootstrap support values (\%) were calculated based on 500 bootstrap replicates. Our new sequences have been deposited in GenBank under the following accession numbers: KY434160 (rDNA, normal sporophyte), KY434161 (rDNA, parthenosporophyte), KY434162 (RuBisCo, normal sporophyte), KY434163 (RuBisCo, parthenosporophyte), KY434164 (COI, normal sporophyte), KY434165 (COI, parthenosporophyte).

\section{Nuclei staining and chromosome observation}

For nuclei staining, $1 \mathrm{mg} \mathrm{mL}^{-1}$ stock solution of DAPI (4',6-diamidino-2-phenylindole; Sigma, St. Louis, MO, USA) dissolved in distilled water was applied to the cross-sectioned materials incised from different parts of the blades at a concentration of $5 \mu \mathrm{g} \mathrm{mL} \mathrm{m}^{-1}$ for 5 to 10 min and heated in a microwave for a few seconds. The stained nuclei were examined under a UV filter. In both types of plants (large and dwarf blades), the nuclei were marked and their areas were compared. On the total, we measured 20 nuclei in each type of plant and compared their surface areas. For observation of chromosomes, aceto-carmine solution (carmine $2 \mathrm{~g}$, glacial acetic acid $45 \mathrm{~mL}, \mathrm{ddH}_{2} \mathrm{O} 50 \mathrm{~mL}$ ) was prepared by boiling for $2-3 \mathrm{~h}$ and filtering through several layers of the filter paper. For chromosome staining, 2-3 drops of aceto-carmine solution were applied to the rehydrated and cross-sectioned tissue taken from the meristem zone. Fine sections were put on a slide glass and covered with a cover slip, and heated over the boiler for 1-2 min. Thereafter, the sections were strongly squashed between the slide glass and the cover slip. Chromosomes thus stained were examined with Olympus BX50 microscope while still immersed in the stain. On the total, we marked and counted chromosomes in 7 and 10 nuclei of the large (i.e., normal sporophytes) and dwarf (i.e., parthenosporophytes) plants of $T$. basicrassa, respectively. Because the chromosomes spread out in three dimensions, the numbers were counted by tracing and marking individual chromosomes through stacks of consecutively taken images (Mann and Poulíčková 2010). First, the labeling was accomplished for all nuclei in both types of plants and then counting was performed. 


\section{RESULTS}

\section{Morphology and anatomy, ecology and distribu- tion}

Tauya basicrassa (normal sporophytes). Large sporophytic plants have unique morphology of blade (Table 1, Figs $2 \mathrm{~A}-\mathrm{C} \& 3 \mathrm{~A}$ ); it is very wide, entire or bearing longitudinal clefts in young plants and dissected into 3 or more lobes with age. In fresh plants extracted from the sea, the blades' basal part is narrow, thick, cartilaginous and lighter in color than the rest of the blade (Fig. 3A \& B), looking like a concave-convolute hood with bullations (Fig. 2D \& E). On the contrary, in dried plants the basal part becomes much darker, whereas the upper part becomes lighter (Fig. 2C). The blade's upper part bears 8-9 rows of bullations, is very fragile and crumbles easily, so that only the rigid basal part with stipe remains (Fig. 2D \& E). Stipe is very short, flattened in its upper portion; haptera are rigid, thick and branched (Fig. 3B). In adult plants, the blade's thickness is 1,300-1,360 $\mu \mathrm{m}$ in the basal part and 345-352 $\mu \mathrm{m}$ in the upper part; the medullar layer is 141 and $64 \mu \mathrm{m}$ thick in the basal and upper parts, respectively. Cortex is $12.8 \mu \mathrm{m}$ thick and consists of one layer of pigmented isodiametric cells; beneath the cortex layer very large thickwalled cells are distributed.

Development of bullations begins in the juvenile plants (Fig. 3C \& D). On the blade, bullations are localized between smooth and more thickened ribbon-like stripes; the mature plants usually have 6 of such stripes. Sizes of bullations become gradually larger according to the increase of the blade's width. During the reproductive period occurring from August to early September, sporangial sori begin to develop on these ribbon-like stripes (Fig. 3E), and later the sori spread outside the stripes.

In T. basicrassa, morphological differentiation of thalli begins early in plants' development (Fig. 3C \& D). Although its anatomy is similar to other laminariacean algae, it has some specific characters such as glandular cells (Fig. 3F) and large mucilage ducts up to 77-128 $\mu \mathrm{m}$ in size in the cross-section (Fig. 3G \& H), which spread on the whole basal part and meristem zone of the blade. The mucilage ducts form a conductive system in the tissue (network of channels), which acts as an elastic armature, reinforcing the blade on its surface. The mucilage ducts are absent in the upper part of blade.

In Taui Bay, T. basicrassa inhabits lower border of the phytal zone and is found in places with lower level of hydrodynamics, at depths of 4-22 m, on rocky substrate covered with sand and silt. It has preference for the coldwater bottom layer of the seawater stratum, forming mono-species communities with an average biomass up to $7.5 \mathrm{~kg} \mathrm{~m}^{-2}$ or growing in groups in mixed communities among other laminariacean algae. Under favorable conditions, the largest plants reach 3-6 m long, 1.8-2.2 m wide, and 6.5-7 kg in wet weight.

Our survey on the continental coast of the Sea of Okhotsk revealed that $T$. basicrassa has a broader distribution than previously thought and grows not only in Taui Bay, but in the proximate more southern and northern regions. However, the gigantic plants develop only in the type locality, i.e., in the area close to Nedorazumeniya Island, because of special bottom relief and increased levels of nutrients in this place, which induce an unlimited growth of plants. The plants have smaller sizes not exceeding 1-1.5 $\mathrm{m}$ at length in places with high waves at depths of 5-8 m. In some coastal areas, T. basicrassa occupies the sub-tidal fringe, becoming stubby and not exceeding 45-65 $\mathrm{cm}$ at length. As estimated from studying the morphology of plants and characteristic annual rings on the cross-section of stipes, T. basicrassa can live for no less than 4 years.

Tauya basicrassa (parthenosporophytes). Thallus of this small yellowish-brown kelp has a small holdfast with weakly branched haptera, $1.7 \mathrm{~cm}$-long stipe and a thin, soft, bullate blade reaching $26-34 \mathrm{~cm}$ long and 6-6.5 cm wide. Sculptured bullations are arranged into 4 longitudinal rows, covering the entire blade, forming very distinct longitudinal as well as transverse rows (Fig. 4A \& B). The margins of blade are mostly strait, with several large folds in the upper portion. On overall, blades are thin (up to 102 and 86-99 $\mu \mathrm{m}$ in the basal and upper portions, respectively), becoming slightly thicker towards the edges (Fig. 4D \& E); cortex is $9.6 \mu \mathrm{m}$ thick, composed of one layer of pigmented isodiametric cells, covered with an entire thickened mucilaginous covering on the outer surface (Fig. 4F \& G). Meristoderm is composed of 2-3 layers of large thick-walled cells. Medullar is weakly developed, almost absent. As seen in cross-sections, some cells are filled with brown-red content (Fig. 4D-F). In fresh plants extracted from the sea, the basal part of blade in not different in color than the rest of the blade (Fig. 4B), whereas in dried plants the basal part becomes much darker (lower 1/4 of blade) than the upper part (Fig. 4C). Only sterile plants were collected. As estimated from studying their morphology, these plants were at least 1 year old. 

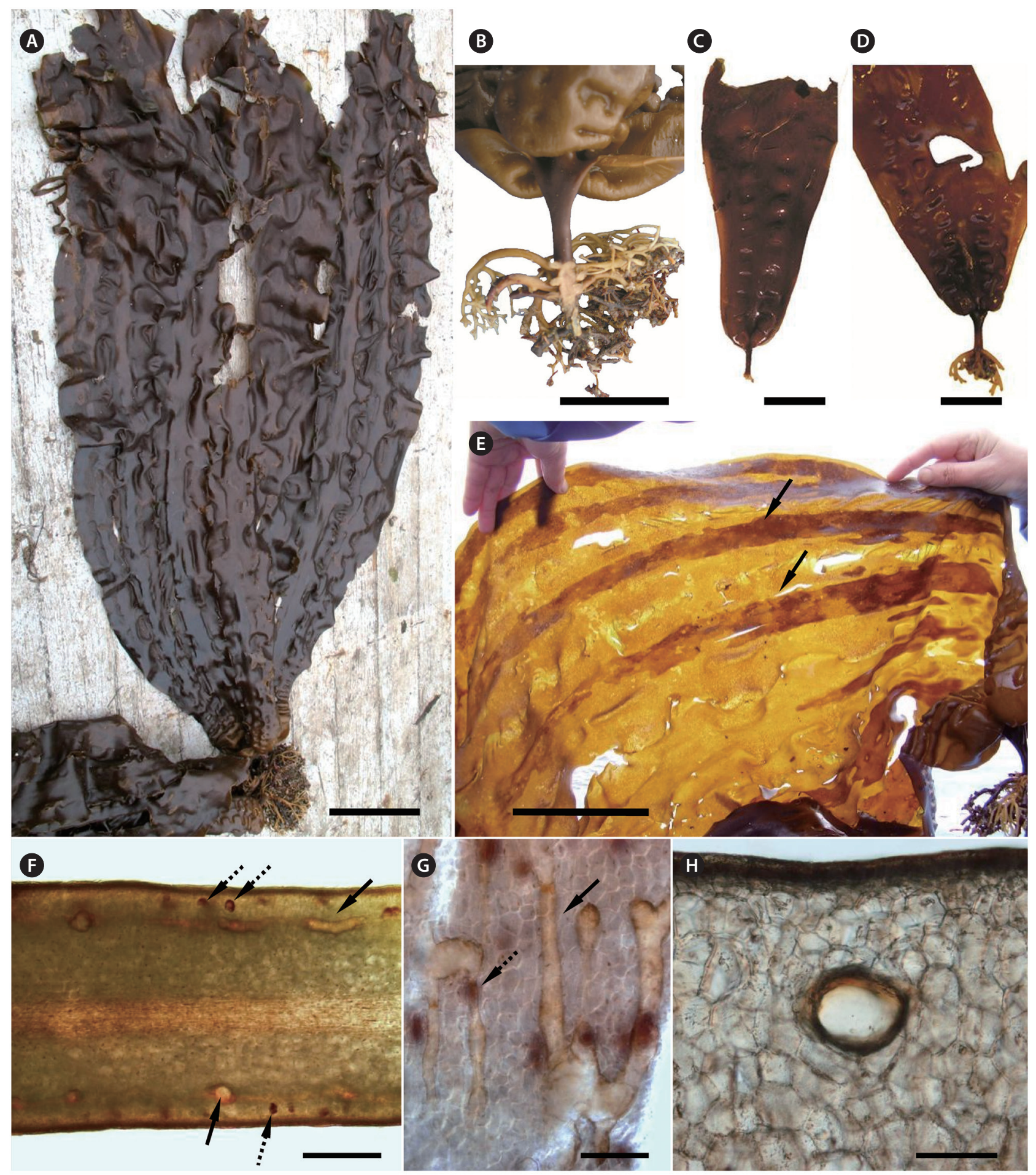

Fig. 3. The morphology and anatomy of normal sporophytes of Tauya basicrassa from the Sea of Okhotsk. (A) Mature plant freshly extracted from the sea. (B) Stipe is short and flattened in the upper portion, and haptera are rigid and branched as seen on the cross-section. (C \& D) Juvenile plants at different state of maturity, showing two (C) and four (D) rows of developing bullations. (E) Sporangial sori in mature plants (arrows, reproduced from Klochkova et al. 2013). (F) Cross-section of blade in the thickenned basal part, showing glandular cells (dashed arrows) and large mucilage ducts (solid arrows). (G) Tangential longitudinal section showing conductive system formed with mucilage ducts, which look similar to a network of channels (solid arrow). Numerous glandular cells can be seen (dashed arrow). (H) Cross-section of mucilage duct. Scale bars represent: A \& E, 10 $\mathrm{cm} ; \mathrm{B}-\mathrm{D}, 5 \mathrm{~cm} ; \mathrm{F}, 500 \mu \mathrm{m} ; \mathrm{G}, 200 \mu \mathrm{m} ; \mathrm{H}, 100 \mu \mathrm{m}$. 


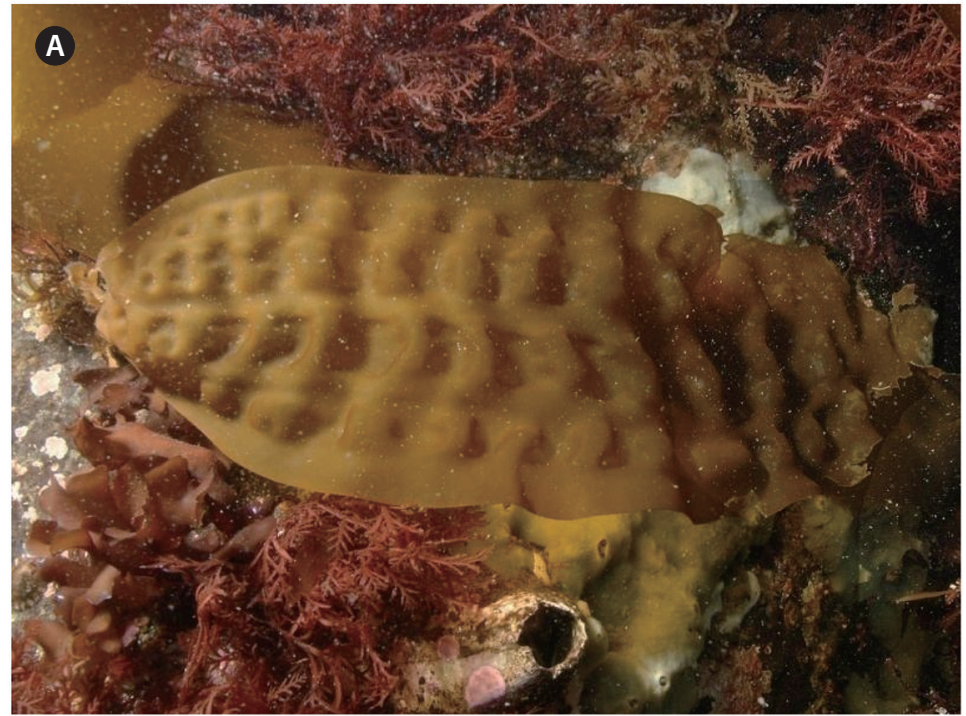

B

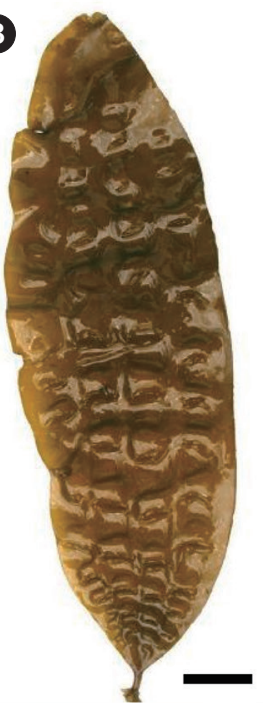

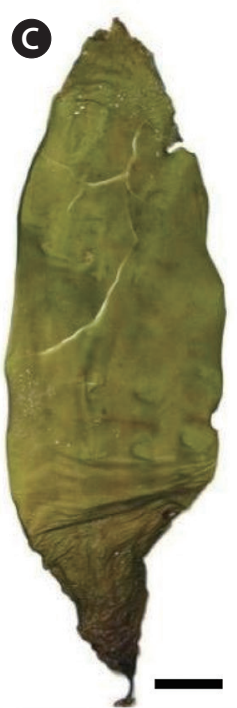

E
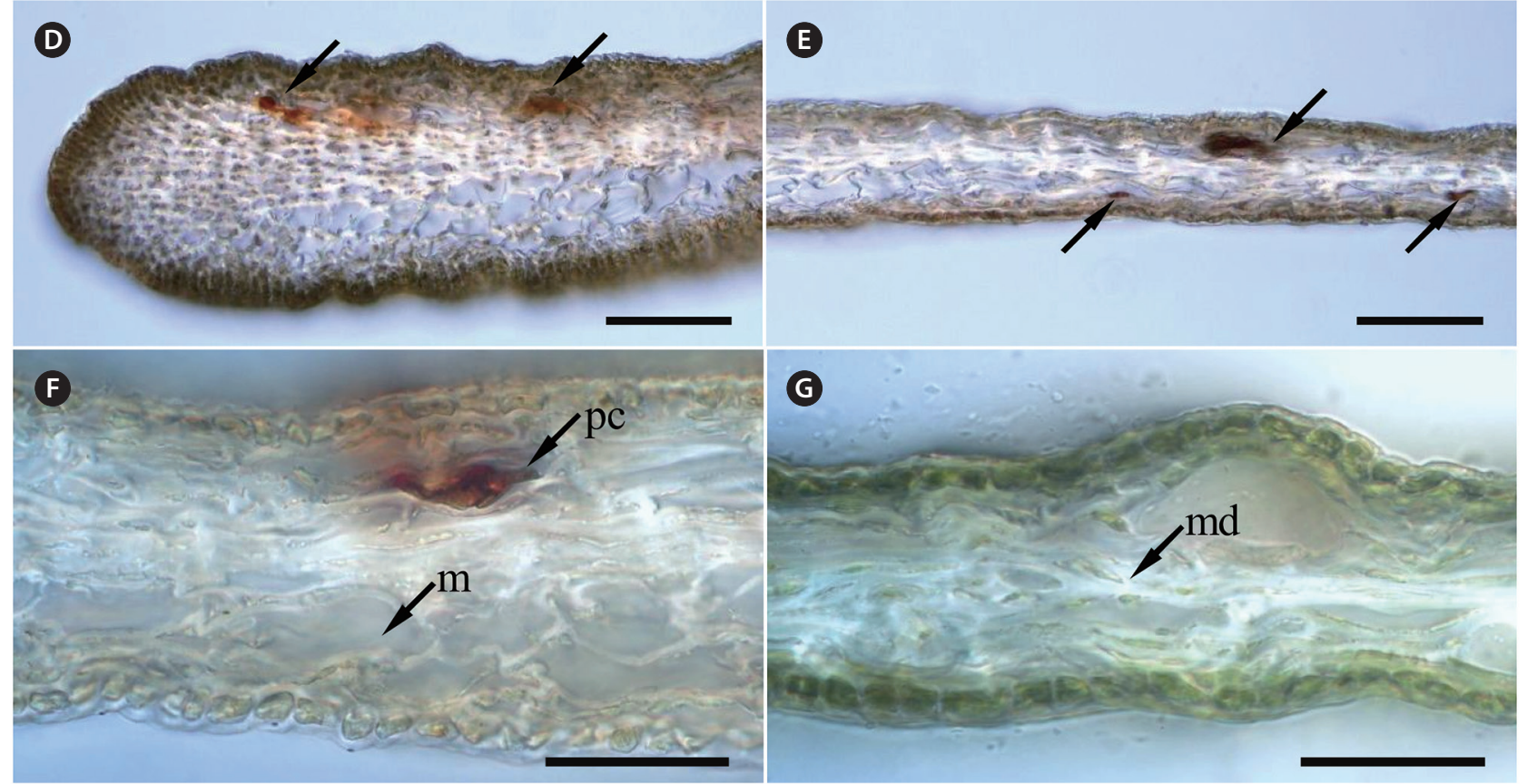

Fig. 4. The morphology and anatomy of parthenosporophytes of Tauya basicrassa from the Sea of Okhotsk. (A) Underwater photograph of mature plant attached to sea bottom. (B) Freshly extracted plant showing four rows of bullations ( $A$ and $B$ are reproduced from Klochkova et al. 2013). (C) Same plant in dried condition showing dark basal part of the blade. (D \& E) The blades are thin and become slightly thicker towards the edges; some cells in the meristoderm are filled with brown-red content (arrows). (F \& G) Cross-sections of the middle part of blade, showing pigmented cell, large cells in the meristoderm and very thin, almost undeveloped medullar. $\mathrm{m}$, meristoderm; md, meddular; $\mathrm{pc}$, pigmented cell. Scale bars represent: B \& C, $2 \mathrm{~cm} ; \mathrm{D} \& \mathrm{E}, 100 \mu \mathrm{m} ; \mathrm{F} \& \mathrm{G}, 50 \mu \mathrm{m}$. 


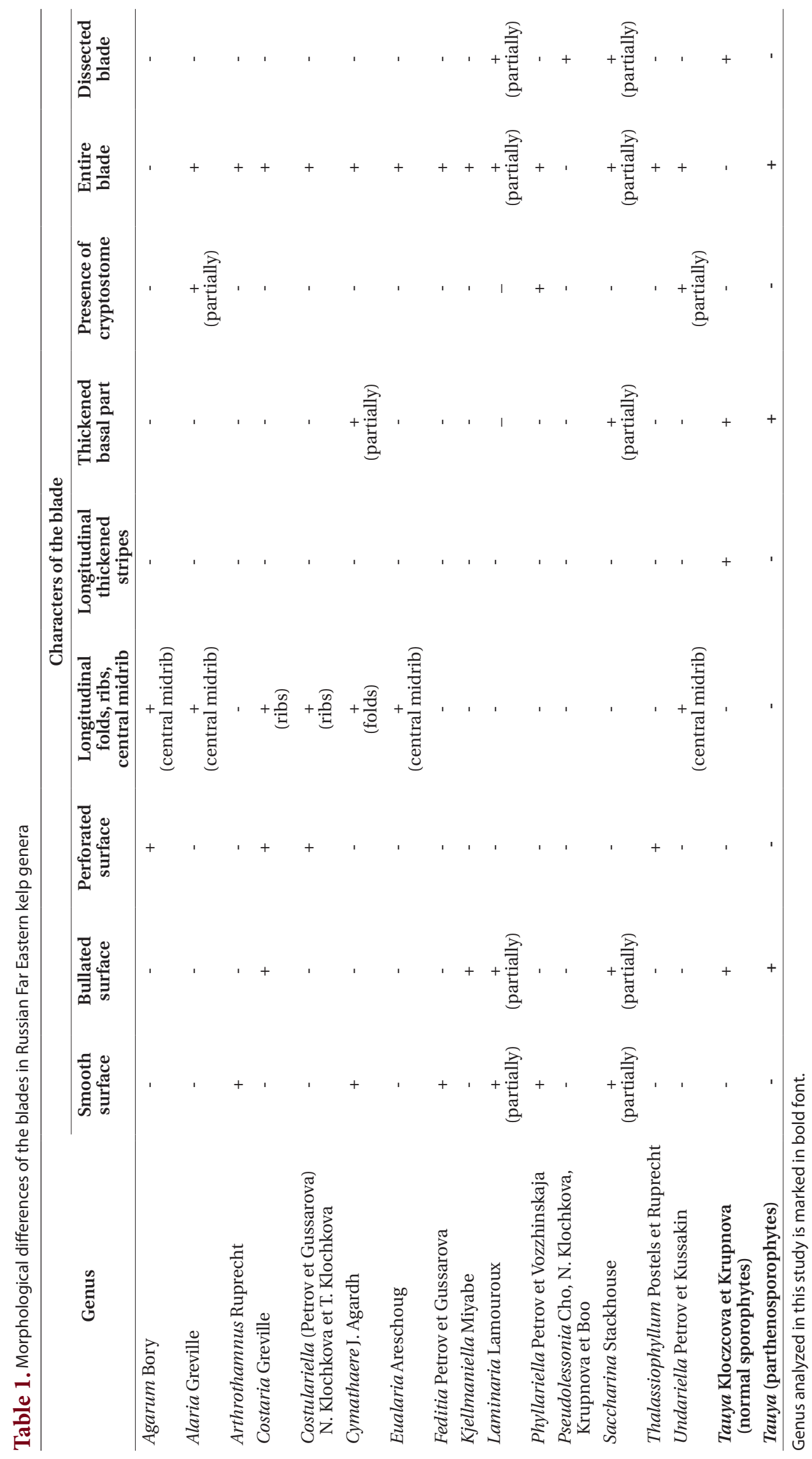




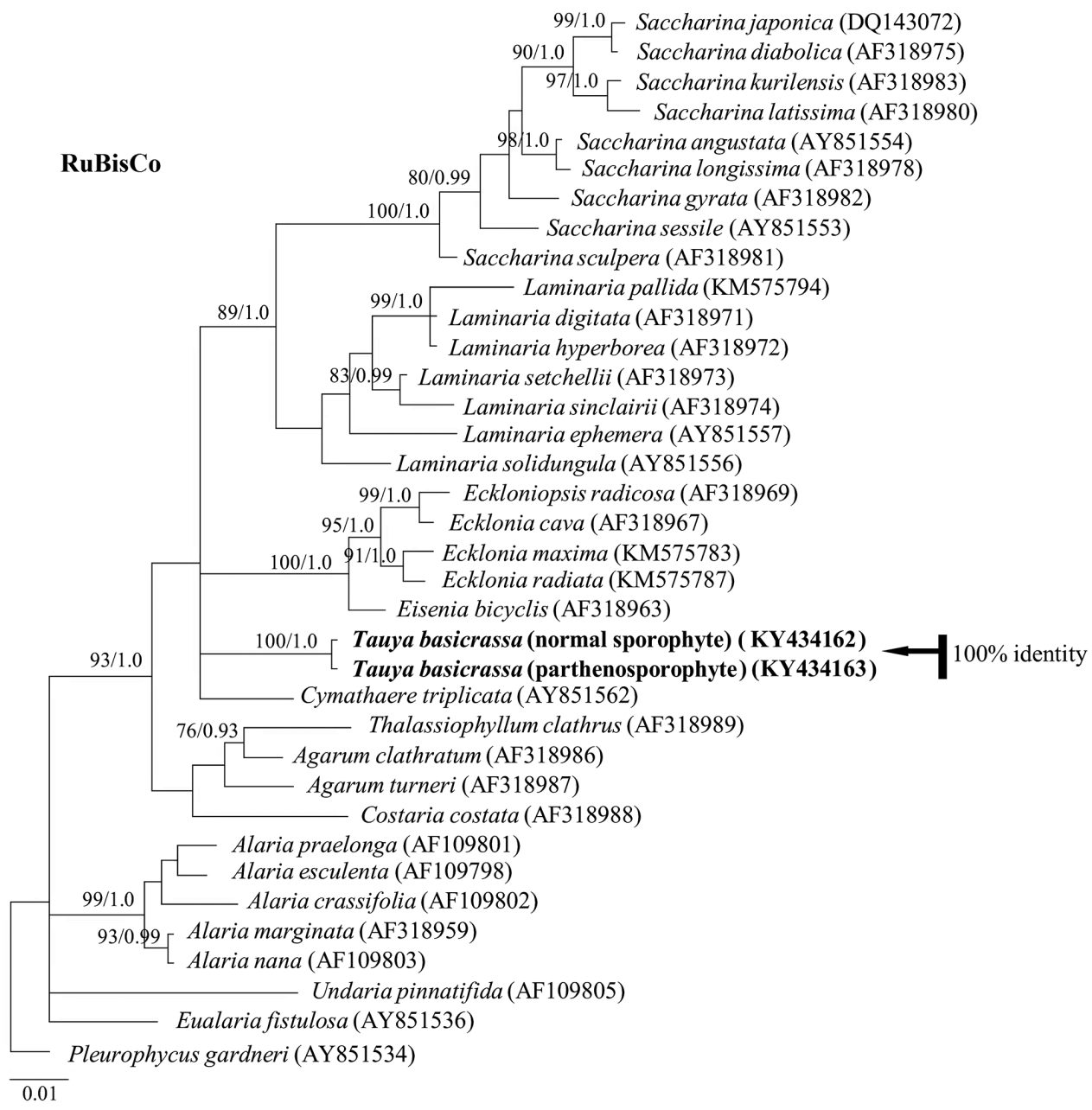

Fig. 5. Bayesian inference of phylogenies of the brown algae belonging to kelp species based on plastid-encoded RuBisCo spacer sequences. Labels on branches are posterior probabilities $(>75)$ and consensus support values. Our new sequences are shown with arrow.

\section{Molecular identification}

Phylogenetic analysis using plastid-encoded RuBisCo spacer, rDNA and COI showed that the giant sporophytes of $T$. basicrassa and bullate small kelp were identical (Figs 5-7). In each tree, they formed a separate well-supported clade and did not fall into any known algal genus sequenced to date. In RuBisCo tree, the "Tauya” clade positioned between the clade formed by five different species from Lessoniaceae and Cymathaere triplicata (Postels et Ruprecht) Agardh from Laminariaceae. In rDNA and COI trees, Tauya belonged to the family Laminariaceae.

\section{Nuclei staining and chromosome observation}

Fluorescent DAPI staining showed that the volume of nuclei in the normal sporophytes of T. basicrassa was by $50-65 \%$ larger than in the parthenosporophytes (Fig. 8A \& B). Chromosomes from the cells in meristem zone of both plants stained with acetocarmine were observed. It was quite difficult to examine the exact shape of chromosomes, as the thick cell walls prevented use of the normal "squash preparation" methods. The shape was dot-like or slightly elongated in both species, sizes were identical, and the numbers were $\mathrm{n}=\mathrm{ca}$. 20 in T. basicrass normal sporophyte and $\mathrm{n}=$ ca. 10 in the parthenosporophyte (Fig. 8C-E). 


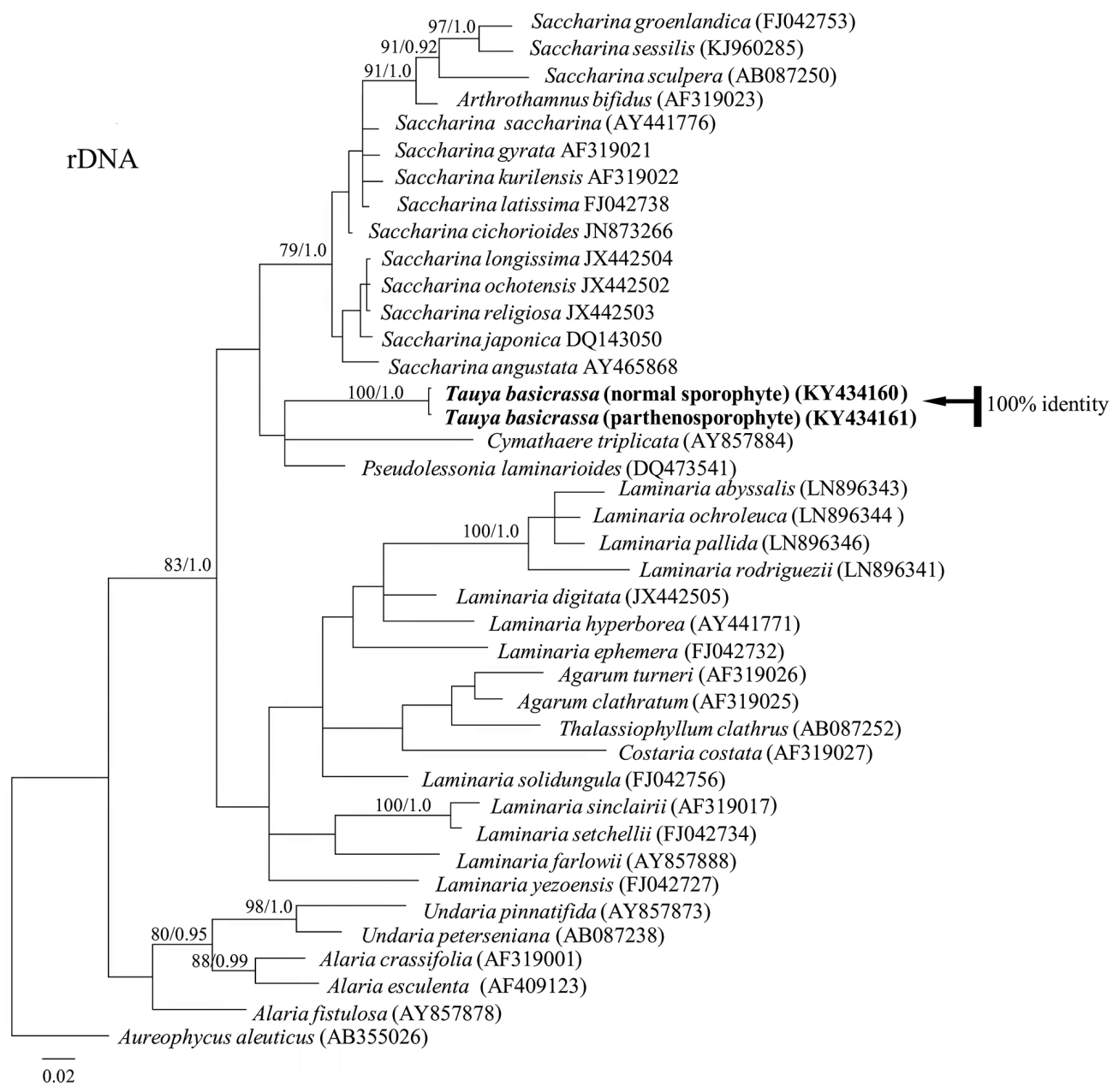

Fig. 6. Bayesian inference of phylogenies of the brown algae belonging to kelp species based on rDNA regions sequences (18S rRNA, ITS1, 5.8S rRNA, ITS2, 26S rRNA). Labels on branches are posterior probabilities (>75) and consensus support values. Our new sequences are shown with arrow.

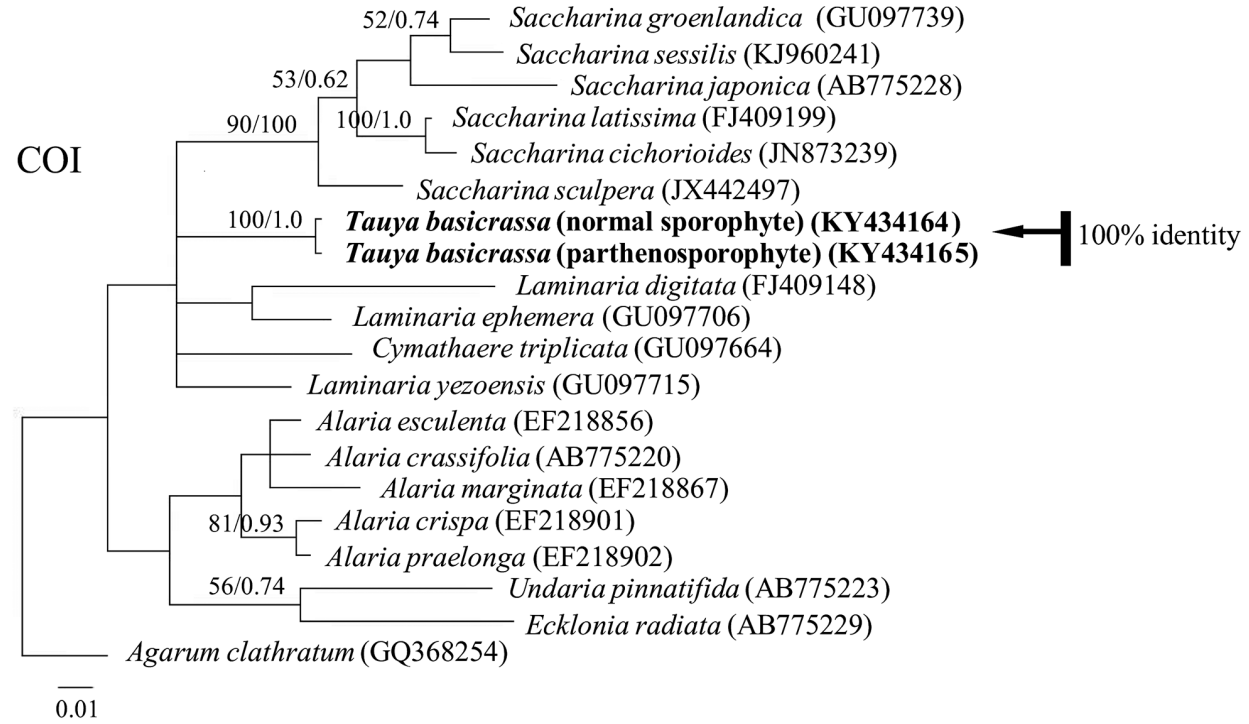

Fig. 7. Bayesian inference of phylogenies of the brown algae belonging to kelp species based on cytochrome c oxidase subunit 1 (COI) sequences. Labels on branches are posterior probabilities and consensus support values. Our new sequences are shown with arrow. 


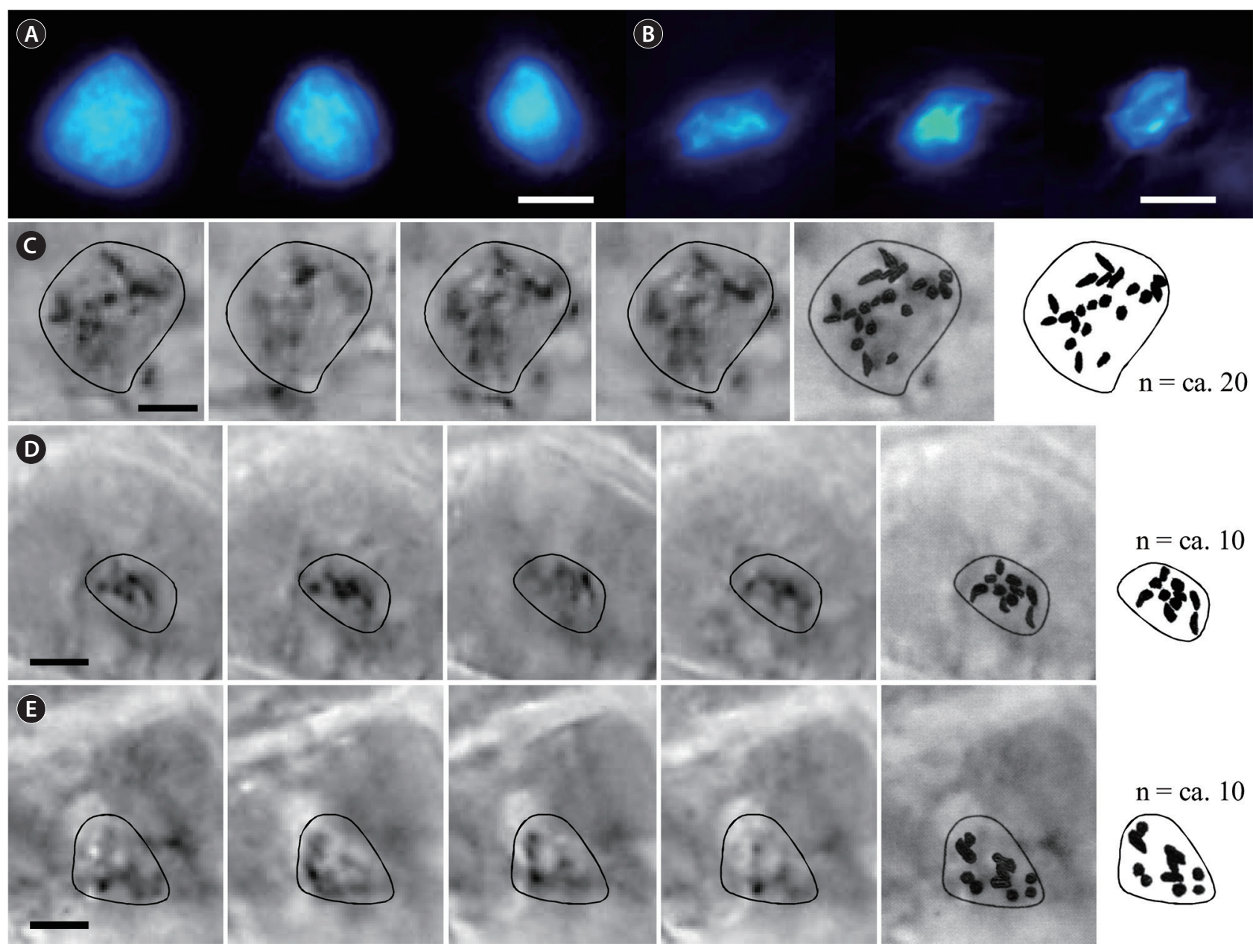

Fig. 8. Fluorescent DAPI staining of nuclei and acetocarmine staining of chromosomes of normal sporophytes and parthenosporophytes of Tauya basicrassa. (A) Large nuclei of normal sporophytes. (B) Small nuclei of parthenosporophytes. (C) Selected through-focus images of chromosomes in the large nuclei of normal sporophytes and chromosome counting. (D \& E) Selected through-focus images of chromosomes in the small nuclei of parthenosporophytes and chromosome counting. Scale bars represent: A-E, $5 \mu \mathrm{m}$.

\section{DISCUSSION}

Morphological characteristics of the genus Tauya are clearly different from other laminariacean species (Klochkova and Krupnova 2004), but it has long been treated as Laminariales familia incertae sedis (uncertain family) because there has been no molecular data supporting the establishment of the genus (Guiry and Guiry 2016). Our molecular analysis based on rDNA and COI genes suggested attribution of Tauya to the family Laminariaceae, which is also in agreement with morphological characters of this genus.

T. basicrassa was originaly described as an endangered endemic species with very narrow distribution on a small area of sea bottom characterized by specific hydrological conditions (Klochkova and Krupnova 2004). The type lo- cality of T. basicrassa was the small area on the sea bottom located inside Taui Bay between Nedorazumeniya Island and continental coast (mainland). This area not exceeding $1 / 3$ of a square kilometer looks like a deep trench in the sea, with a substrate made with rocks, pebbles and sand. Because of such peculiar bottom relief, large depth, and overall appearance of the coastline, seawater mixing in the bottom layer is weak, resulting in increased nutrients concentration, which in turn causes an unlimited growth of T. basicrassa sporophytes. In some sites of this bottom, it formed mono-species communities at 15-17 m deep.

Some kelp species have been reported to have narrow distribution (Petrov and Gussarova 1972, Petrov and Kussakin 1997, Lee and Yoon 1998, Kawai et al. 2008, Klochkova and Klochkova 2010). Other laminariacean algae have 
discontinuous distributions and populations of the same species can be found at large distances. For example, $A r$ throthamnus kurilensis Ruprecht is mainly distributed on the Kurile Islands, but another isolated population exists on the south of Sakhalin Island on a small area of sea floor characterised by upwelling of cold bottom waters (called "Makarov's spot" in Russian) (Klochkova 1998). Laminaria gurjanovae Zinova also has discontinuous distribution on the Russian Far East. Thus, a small deep-water population of T. basicrassa near Nedorazumeniya Island also seemed like a relict population of once widespread species. Although all plants from this area became gigantic, the increase in size was accompanied by a significant decrease in the thickness of blade. Such changes occur in plants when they grow in seawater with low mobility and high nutrients concentration, because the lack of laminar flow, which is supposed to bring nutrients to the blade's surface, is compensated by an increased absorbing surface area. For example, we observed very large plants of Sacharina bongardiana on the north-eastern Kamchatka in Yuzhnaya Glubokaya Bay in the exit site of underwater fumaroles (Klochkova and Berezovskaya 1997). Gussarova (1975) reported on seaweed gigantism from the Kurile Islands due to the enrichment of coastal seawaters with volcanic ashes.

During hydrobiological expedition on the northern continental coast of the Sea of Okhotsk (Klochkova et al. 2013) we confirmed that $T$. basicrassa does not have wide distribution in this area. It usually inhabits places with low level of hydrodynamics, at depths of 4-22 m, showing preference for the cold bottom layer (12-18 $\mathrm{m}$ deep). Its distribution border usually coincided with the replacement of hard substrates (i.e., rocks, boulders) with soft substrate (i.e., sand), and most commonly it inhabited sandy silted bottom with more or less frequent boulders, to which it attached. It did not grow in clusters of plants or forming dense covers on the bottoms, and the maximum number of plants per 1 square meter was 5-7. Under favorable conditions it formed mono-species communities with an average biomass of $7.5 \mathrm{~kg} \mathrm{~m}^{-2}$.

A dwarf kelp, which is morphologically unassignable to any known species of laminariacean algae, was found on rocks and boulders at 4-7 $\mathrm{m}$ deep in the same locality. This dwarf laminariacean alga distributed sparsely in that area and never grew in groups (Klochkova et al. 2013). During analysis of the underwater videos of seaweed beds from other areas of Taui Bay, we also found several more plants with same size and morphology. Although their morphol- ogy was dramatically different from normal sporophytes of T. basicrassa our molecular data showed that the dwarf one is just a different life form of $T$. basicrassa. Comparative study of their karyotypes showed that this morphological variation is due to the difference in ploidy levels. Chromosome number of dwarf plants was half of that in the normal sporophytes of T. basicrassa. Although no reproductive structures were found on the collected materials, the dwarf thallus has probably derived parthenogenetically from unfertilized eggs of T. basicrassa.

In laboratory culture, unfertilized eggs of laminariacean algae are known to develop parthenogenetically, but those plants were usually shaped abnormal and died ephemerally (Ar Gall et al. 1996). Development of parthenosporophytes under laboratory conditions has been reported in many kelp species (Fang and Dai 1980, Lewis et al. 1993, Oppliger et al. 2007, Shan et al. 2013). In Saccharina japonica (Areschoug) Lane, Mayes, Druehl et Saunders, female parthenosporophytes developed zoospores, which grew into microscopic female gametophytes, produced eggs later, fused with male sperms of this species and developed into normal diploid sporophytes (Lewis et al. 1993). To the best of our knowledge, our results are the first example of parthenogenesis and / or apogamy in the laminariacean algae demonstrated to occur naturally in the field. It is noteworthy that the parthenosporophytes were at least 1 year old because they were overwintered plants. Further studies on the life history of $T$. basicrassa using laboratory culture may reveal the mechanisms that govern differential morphogenesis occurring in sporophytes and gametophytes of laminariacean algae.

\section{ACKNOWLEDGEMENTS}

This work was supported by a National Research Foundation of Korea Grant (NRF-2015M1A5A1041804) funded to GHK. This research was also supported by Golden Seed Project, Ministry of Agriculture, Food and Rural Affairs, and a grant from Marine Biotechnology Program (PJT200620, genome analysis of marine organisms and development of functional applications) funded by Ministry of Oceans and Fisheries, Korea. We thank Dr. Belij, M. N. (MagadanNIRO) for his help during samples collection from the Taui Bay. We thank Dr. Alejnikova, M. D. (Editorial board of "International Journal on Algae," Algologia) for permission to reproduce picture of the holotype. 


\section{REFERENCES}

Ar Gall, E. (Le Gall, Y.), Asensi, A., Marie, D. \& Kloareg, B. 1996. Parthenogenesis and apospory in the Laminariales: a flow cytometry analysis. Eur. J. Phycol. 31:369-380.

Belij, M. N. 2013. Seaweeds of the northern part of the Sea of Okhotsk and their role as a substrate for the herring spawning. Federal Agency of Fishery of Russian Federation, Magadan Scientific-Research Institute of Fishery and Oceanography (MagadanNIRO), Magadan, 193 pp. (in Russian).

Boo, G. H., Lindstrom, S. C., Klochkova, N. G., Yotsukura, N., Yang, E. C., Kim, H. G., Waaland, J. R., Cho, G. Y., Miller, K. A. \& Boo, S. M. 2011. Taxonomy and biogeography of Agarum and Thalassiophyllum (Laminariales, Phaeophyceae) based on sequences of nuclear, mitochondrial, and plastid markers. Taxon 60:831-840.

Cho, G. Y., Klochkova, N. G., Krupnova, T. N. \& Boo, S. M. 2006. The reclassification of Lessonia laminarioides (Laminariales, Phaeophyceae): Pseudolessonia gen. nov. J. Phycol. 42:1289-1299.

Fang, Z. X. \& Dai, J. X. 1980. Use of haploid phases in the genetic study of Laminaria japonica. Acta Genet. Sin. 7:1925 .

Guiry, M. D. \& Guiry, G. M. 2016. AlgaeBase. World-wide electronic publication, National University of Ireland, Galway. Available from: http://www.algaebase.org. Accessed Oct 10, 2016.

Gussarova, I. S. 1975. Macroalgae of the sub-tidal zone of Iturup, Urup and Simushir Islands (large Kurile Islands). Novosti Sistematiki Nizshih Rastenii [News on Systematics of Non-vascular Plants] 12:111-118 (in Russian).

Huelsenbeck, J. P. \& Ronquist, F. 2001. MRBAYES: Bayesian inference of phylogenetic trees. Bioinformatics 17:754755 .

Kawai, H., Hanyuda, T., Lindeberg, M. \& Lindstrom, S. C. 2008. Morphology and molecular phylogeny of Aureophycus aleuticus gen. et sp. nov. (Laminariales, Phaeophyceae) from the Aleutian Islands. J. Phycol. 44:10131021.

Klochkova, N. G. 1998. Flora of macroalgae of the Russian Far East. Extended Abstract of National Doctoral Degree Dissertation, Vladivostok, 49 pp. (in Russian).

Klochkova, N. G. \& Belij, M. N. 2006. Additional information to the description of Tauya basicrassa Kloczcova et Krupnova from the Sea of Okhotsk. In Tokranov, A. M. (Ed.) Conservation of Biodiversity of Kamchatka and Coastal Waters. Petropavlovsk-Kamchatsky Press, Petropavlovsk-Kamchatsky, pp. 391-394 (in Russian).

Klochkova, N. G. \& Belij, M. N. 2010. Finding an unusual lam- inariaceaen alga from Taujskaya Bay (Sea of Okhotsk). Bull. Kamch. State Tech. Univ. [Vestnik KamchatGTU] 11:55-58 (in Russian).

Klochkova, N. G. \& Berezovskaya, V. A. 1997. The seaweeds of Kamchatka's shelf: biology, distribution, chemical composition. Dalnauka, Vladivostok, 153 pp. (in Russian).

Klochkova, N. G. \& Klochkova, T. A. 2010. Costulariella, a new substitute name for Costularia Ju. Petrov et I. Gussarova (Laminariales, Phaeophyceae). Algae 25:183-185.

Klochkova, N. G. \& Krupnova, T. N. 2004. New and interesting taxa of laminarialeaen algae (Laminariales, Phaeophyta) of Far Eastern seas of Russia. Tauya basicrassa Kloczc. et Krupn. gen. et sp. nov. Algology 14:86-94 (bilingual, Russian-English).

Klochkova, T. A., Belij, M. N. \& Klochkova, N. G. 2013. Chapter 3. Seaweeds of the Sea of Okhotsk. In Volobuev, V. V. \& Klochkova, N. G. (Eds.) Seaweeds of the Northern Part of the Sea of Okhotsk and Their Role as a Substrate for the Herring Spawning. Federal Agency of Fishery of Russian Federation, Magadan Scientific-Research Institute of Fishery and Oceanography (MagadanNIRO), Magadan, pp. 21-140 (bilingual, Russian-English).

Klochkova, T. A., Kim, G. H., Belij, M. N. \& Klochkova, N. G. 2012. Morphology and phytogeography of Laminaria appressirhiza and L. inclinatorhiza (Phaeophyceae) from the Sea of Okhotsk. Algae 27:139-153.

Klochkova, T. A., Kim, G. H., Lee, K. M., Choi, H. -G., Belij, M. N. \& Klochkova, N. G. 2010. Brown algae (Phaeophyceae) from Russian Far Eastern seas: re-evaluation of Laminaria multiplicata Petrov et Suchovejeva. Algae 25:77-87.

Lane, C. E., Lindstrom, S. C. \& Saunders, G. W. 2007. A molecular assessment of northeast Pacific Alaria species (Laminariales, Phaeophyceae) with reference to the utility of DNA barcoding. Mol. Phylogenet. Evol. 44:634-648.

Lane, C. E., Mayes, C., Druehl, L. D. \& Saunders, G. W. 2006. A multi-gene molecular investigation of the kelp (Laminariales, Phaeophyceae) supports substantial taxonomic re-organization. J. Phycol. 42:493-512.

Lee, Y. -P. \& Yoon, J. -T. 1998. Taxonomy and morphology of Undaria (Alariaceae, Phaeophyta) in Korea. Algae 13:427-446.

Lewis, R. J., Jiang, B. Y., Neushul, M. \& Fei, X. G. 1993. Haploid parthenogenetic sporophytes of Laminaria japonica (Phaeophyceae). J. Phycol. 29:363-369.

Mann, D. G. \& Poulíčková, A. 2010. Mating system, auxosporulation, species taxonomy and evidence for homoploid evolution in Amphora (Bacillariophyta). Phycologia 49:183-201.

National Center for Biotechnology Information (NCBI). 
2016. GenBank. Available from: http//www.ncbi.nlm. nih.gov. Accessed Oct 10, 2016.

Oppliger, L. V., Correa, J. A. \& Peters, A. F. 2007. Parthenogenesis in the brown alga Lessonia nigrescens (Laminariales, Phaeophyceae) from central Chile. J. Phycol. 43:12951301.

Petrov, Yu. E. \& Gussarova, I. S. 1972. New species and genus of laminariacean alga from Simushir Island. Novosti Sistematiki Nizshih Rastenii [News on Systematics of Non-vascular Plants] 9:39-44.

Petrov, Yu. E. \& Kussakin, O. G. 1997. Undariella kurilensis: new species and genus of laminariacean alga from the littoral zone of Yankich Island (Kurile Islands). Biol. Mor. [Russ. J. Mar. Biol.] 23:79-83 (bilingual, Russian-English).

Saunders, G. W. \& Druehl, L. D. 1993. Nucleotide sequences of the internal transcribed spacers and 5.8S rRNA genes from Alaria marginata and Postelsia palmaeformis (Phaeophyta: Laminariales). Mar. Biol. 115:347-352.

Shan, T. F., Pang, S. J. \& Gao, S. Q. 2013. Novel means for va- riety breeding and sporeling production in the brown seaweed Undaria pinnatifida (Phaeophyceae): crossing female gametophytes from parthenosporophytes with male gametophyte clones. Phycol. Res. 61:154-161.

Stamatakis, A. 2014. RAxML version 8: a tool for phylogenetic analysis and post-analysis of large phylogenies. Bioinformatics 30:1312-1313.

Wynne, M. J. 1982. Phaeophyceae. In Parker, S. P. (Ed.) Synopsis and Classification of Living Organisms. McGraw-Hill, New York, NY, pp. 115-125.

Yoon, H. S. \& Boo, S. M. 1999. Phylogeny of Alariaceae (Phaeophyta) with special reference to Undaria based on sequences of the RuBisCo spacer region. Hydrobiologia 398/399:47-55.

Yoon, H. S., Lee, J. Y., Boo, S. M. \& Bhattacharya, D. 2001. Phylogeny of Alariaceae, Laminariaceae, and Lessoniaceae (Phaeophyceae) based on plastid-encoded RuBisCo spacer and nuclear-encoded ITS sequence comparisons. Mol. Phylogenet. Evol. 21:231-243. 